Journal of Research in Interprofessional

Practice and

Education

Vol. 3.1

March, 2013
Journal of Research in Interprofessional Practice and Education (JRIPE)

Vol. 3.1

(c) 2013

Corresponding author: Ainsley Moore. Email: 'ainsleyemoore@gmail.comı!

\section{Physician and Nurse Perspectives of an Interprofessional and Integrated Primary Care-Based Program for Seniors}

\author{
Ainsley Elizabeth Moore, MSc, MD, CFPC; \\ Kalpana Nair, MSc, PhD; Christopher Patterson, MD, FRCP; \\ Joy White, PHCNP, Master's of Nursing; Shelly House, BScPharm; \\ Amjed Kadhim-Saleh, BSc, MSc, MD (Cand.); \& John Riva, DC
}

\begin{abstract}
Background: In Canada, primary care practitioners provide the majority of care for elderly patients. Increasing volume and complexity of care compounded by a shortage of specialized geriatric services has lead to problems of fragmented, inefficient, and often ineffective service for this population. Integrated models that bridge primary and secondary care have emerged as a major theme in health reform to address such challenges for care of the elderly. Although primary care practitioners are important stakeholders necessary for successful uptake and sustainability of such integrated models, this perspective has been largely unexplored.

Methods and Findings: We used a qualitative thematic approach to bring forward front-line perspectives of nurses and physicians who referred their patients to a newly developed integrated, multidisciplinary program for seniors that was introduced into their primary care clinic. Referrers experienced improved care processes, improved quality of care, as well as an enhanced experience when managing their elderly patients. Unclear assignment of roles and responsibilities created confusion for referring practitioners and their patients.

Conclusions: Understanding benefits, limitations, and changes to front-line practitioner experience provides insight into important factors contributing to buy-in and sustainability of integrated programming for the elderly in this setting.

Keywords: Interprofessional; Primary care; Geriatrics; Qualitative
\end{abstract}

\section{Introduction}

\section{Background}

Frail seniors with multiple conditions and complex bio-psychosocial problems represent the fastest-growing segment of the aging population [1]. While primary care practitioners provide the majority of care for these individuals, many barriers and challenges stress our fragmented and often ineffective health service for this population [2]. Many jurisdictions are faced with an aging population and a shortage of specialized geriatric services. In Canada, there are approximately 200 geriatricians serving 3.2 million seniors over 75 years of age [3]. Integrated (multidisciplinary) approaches between primary and secondary care have emerged as a recurrent theme in reform of healthcare for the elderly [4]. Canadian government has promoted and allocated substantial funds to primary care renewal initiatives that emphasize interprofessional teamwork [5]; family health teams introduced in Ontario in 2006 are an example of this initiative [6]. There are over 200 interprofessional family health 
104

Care-Based Program for Seniors

Moore, Nair, Patterson, White, House, KadhimSaleh, \& Riva

Journal of Research in Interprofessional Practice and Education

Vol. 3.1

March, 2013 teams in Ontario that are uniquely positioned to serve the needs of complex patients, such as frail seniors. The emergence of such interprofessional primary care teams have fostered "grass-roots" team-based integrated initiatives that provide programming for elderly patients with complex health problems $[7,8]$

\section{Present knowledge}

There are numerous multidisciplinary, integrated primary care geriatric models, variously described as guided care [9,10], home-based care [11,12], interdisciplinary transition care [13], collaborative care $[14,15,16]$, integrated case management [17], comprehensive team care [18], and all-inclusive care [19]. Teams are typically composed of practitioners from nursing, social work, psychology, psychiatry, geriatric medicine, geriatric psychiatry, physiotherapy, occupational therapy, internal medicine, and family medicine [20]. Patient populations often include seniors with dementia [14], depression [21-25], arthritis [26], as well as minority groups [22], veterans [13], house-bound [11,12], complex [27], palliative [18], and low-income seniors [28]. Evaluations of interdisciplinary teams have mainly focused on patient and their informal caregivers $[11,19,29]$. Enhanced care processes of reduced wait times to access specialized services, increased pneumonia vaccination rates, and improved medication prescribing were reported $(19,20,30)$.

\section{Gaps in knowledge}

Primary care practitioners involved with (or whose patients are involved with) integrated programs have been identified as key stakeholders for successful implementation and uptake [6]. It has been recommended that practitioner satisfaction should be measured in all interdisciplinary care management programs [31], although few studies have evaluated their perspectives in this context [31]. Studies that considered this perspective [28,30-32] were limited to quantitative surveys that evaluated physician satisfaction with various elements of the team's intervention, but it was generally not studied as a main outcome measure. Overall, physicians were satisfied with team interventions and particularly valued increased availability of resources for their patients [28,30-32). Even fewer qualitative studies have explored health practitioner experience with integrated care of the elderly. One qualitative study in Ontario, Canada, used focus groups to gain a deeper understanding of the experience of health professionals delivering interprofessional home care for older adults at risk of falling [11]. Overall, team members found that this program created a climate that promoted a shared vision of patient goals and better understanding of each other's roles, contributing to perceived team effectiveness and ultimately improved patient care [11]. Another qualitative evaluation found relational tensions between practitioners and impaired team effectiveness, potentially limiting quality of care in a longterm care setting [33]. Focus groups with psychiatrists, family physicians, social workers, and dieticians participating in a shared mental health primary care program identified flexibility, communication/collaboration, educational opportunities, access to patient information, continuity of care, and maintenance of practitioner and patient satisfaction as major strengths of the program [34]. Shared care was 
Care-Based Program for Seniors

Moore, Nair, Patterson, White, House, KadhimSaleh, \& Riva

Journal of Research in Interprofessional Practice and Education

Vol. 3.1

March, 2013
Journal of Research in Interprofessional Practice and Education

described as highly dependent on communication style, skill and expertise, availability, and attitudes toward shared care [35]. Qualitative evaluations that focus on the experience of primary care practitioners referring their community-dwelling elderly patients to integrated, interdisciplinary programs has not been explored.

Practitioners at Stonechurch Family Health Centre (SFHC) (an interprofessional primary care centre), in conjunction with colleagues from geriatric medicine and community agencies, developed and implemented a multidisciplinary, integrated program for seniors at SFHC. This centre serves over 15,000 patients, including approximately 750 seniors over 75 years of age, and is one of two academic practice units that form the McMaster Family Health Team, Department of Family Medicine (McMaster University, Hamilton, Ontario, Canada) [5].

The purpose of our study was to gain a greater understanding of the perspectives of family physicians and nurses at SFHC that referred their patients to the newly developed integrated, multidisciplinary program, the Seniors Collaborative Care Program (SCCP), between November 2008 and November 2009. Their unique experience provides front-line knowledge of advantages, disadvantages, benefits, and limitations of this integrated program. This study has implications for program uptake and sustainability in the current milieu of primary care reform initiatives and re-distribution of resources from hospital to community that are occurring across every province in Canada as well as other jurisdictions [35]. Understanding how satisfied referring clinicians were with the SCCP will contribute critical knowledge about factors that may promote or detract from sustained uptake of this program.

\section{Program description}

\section{Theoretical underpinnings}

The framework for the Seniors Collaborative Care Program (SCCP) was based on the Shared Mental Health Care model, Hamilton Family Health Team [35]. The model emphasizes the central role of primary care practitioners as the cornerstone of the healthcare system and the natural partnerships between specialists and primary care providers. Collaborative relationship building is the key feature of the framework, leading toward better-integrated and more efficient healthcare delivery that is aligned with concurrent reforms of primary care taking place across Canada. Potential benefits for patients are enhanced quality of care and improved access to specialized care. Potential benefits for primary care practitioners are increased comfort and skill when managing complex health problems and increased effectiveness on the part of specialists as consultants and supports for primary care providers. The health system may benefit from a more efficient use of available resources, as well as addressing barriers that impede integration of primary care reform and may lead to prevention or early detection of health problems.

\section{SCCP team composition}

The Seniors Collaborative Care Program (SCCP) core team is located within the SFHC and is composed of one nurse practitioner (NP), one family physician (FP), 


\section{JRIPE}

106

Care-Based Program for Seniors

Moore, Nair, Patterson, White, House, KadhimSaleh, \& Riva

and one registered practical nurse (RPN), all with over 5 years' experience in primary care of the elderly. Additional SCCP members include a pharmacist, social worker, occupational therapist, and visiting geriatrician. All practitioners, with the exception of the geriatrician, are employed at SFHC. Funding support for the geriatrician is provided by the McMaster Family Health Team ( 3 hours per month), and this inclusion of secondary (specialized geriatric) care in the primary care setting is a unique component of the SCCP. The NP additionally provides an important patient co-ordination and administrative role. The SCCP was piloted at SFHC between November 2008 and November 2009 and has continued to operate.

\section{Patient flow and program logistics}

Figure 1 illustrates patient flow through the program. The early pilot phase of the program (November 2008 to June 2009) made use of telephone screening to identify seniors at risk of falling and dementia. This recruitment method was found to be inefficient, resource intensive, and not representative of usual practice, and it was subsequently replaced by a referral process. Between July and November 2009, healthcare practitioners at SFHC were invited to refer any elderly patient to the SCCP that they felt could benefit from the program. Twenty-five patients were referred to the pilot program (approximately 5 per month). Table 1 summarizes patient demographics, screening results, and reasons for referral during the pilot study.

\section{Figure 1: Care path for SCCP patients}

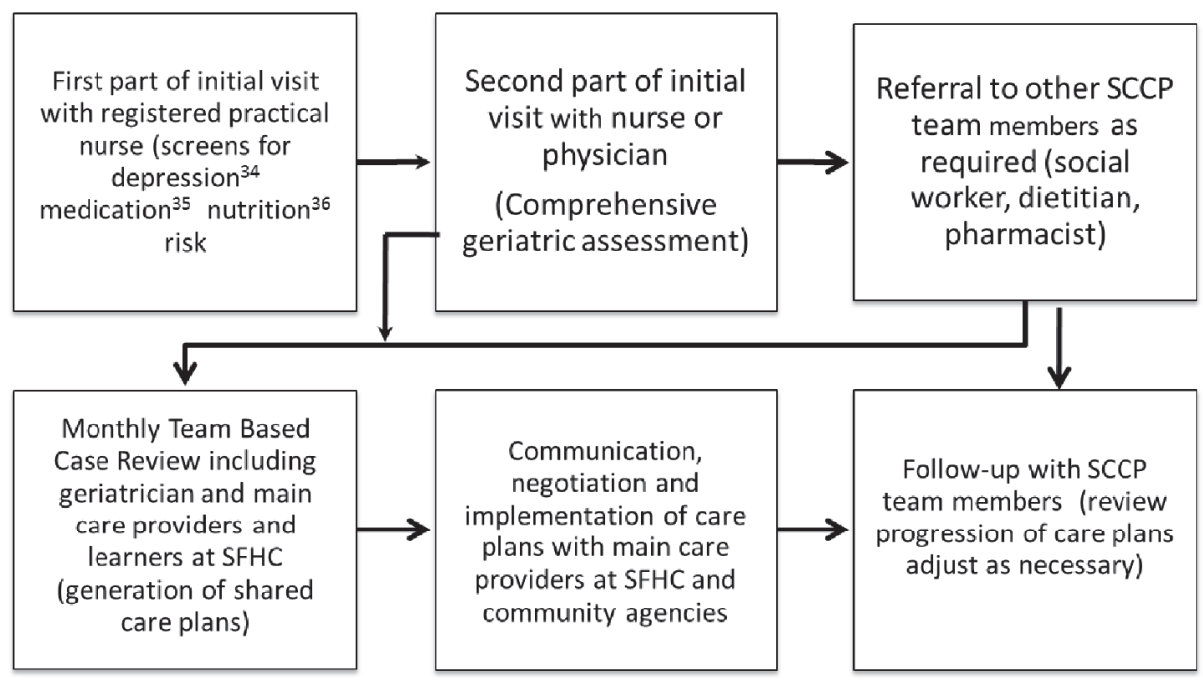

Legend for Figure 1

1. Screen for risk of depression, using Geriatric Depression Scale-Short Form [34]

2. Screen for risk of medication complications, using Levy Medication Risk Questionnaire [35]

3. Screen for risk of nutritional impairment, using SCREEN II [36]

Patients were seen by the SCCP within 4-6 weeks of referral. This compares to 


\section{JRIPE}

107

Care-Based Program for Seniors

Moore, Nair, Patterson, White, House, KadhimSaleh, \& Riva gram RPN, who conducted evaluations to determine risk of depression, medication complications, and nutritional impairment, using the Geriatric Depression Scale (short form) [36], the Levy Medication Risk Questionnaire [37], and the SCREEN II [38], respectively. The program nurse practitioner or family physician subsequently conducted standardized assessments (1-hour appointment) at the same visit, employing relevant quality indicators to address presenting issues such as the management and prevention of falls [39], and the diagnosis and treatment of dementia [40]. Visits with all providers, including the geriatrician, occurred at SFHC or in the patient's own home (2 patients). The SCCP is additionally supported by linkages with community agencies such as the Alzheimer's Society and the Community Care Access Centre, which coordinate services to support independent living.

Table 1: Characteristics of referred pilot patients $(n=25)$

\begin{tabular}{|l|l|}
\hline Age Mean (SD) & $81(5.5)$ \\
\hline Males $(n=9)$ : Females $(n=16)$ & $1: 1.7$ \\
\hline Reason for referral: & \\
\hline Multimorbidity (> 3 conditions, or syndromes) & $39 \%$ \\
\hline Functional decline & $28 \%$ \\
\hline Falling & $23 \%$ \\
\hline Cognition concerns & $54 \%$ \\
\hline Mean Wait time in days (SD) & $29(14)$ \\
\hline Screening Results: & $21(7)$ \\
\hline $\begin{array}{l}\text { MOCA* Mean (SD) [1] } \\
\text { Score }<26 \text { risk of cognitive impairment }\end{array}$ & $4(2)$ \\
\hline $\begin{array}{l}\text { GDS** Mean (SD) } \\
\text { Score }>5 \text { risk of depression }\end{array}$ & $47(6)$ \\
\hline $\begin{array}{l}\text { Nutrition SCREEN\# } \\
\text { Mean (SD) } \\
\text { Score > 54 suggestive of eating or nutritional problem }\end{array}$ & $3.5(1.8)$ \\
\hline $\begin{array}{l}\text { Medication Screen\#\# } \\
\text { Mean (SD) } \\
\text { Score }>3 \text { risk of medication complications }\end{array}$ \\
\hline
\end{tabular}

There was no formal additional training undertaken by the RPN, NP, or FP to conduct evaluations or standardized assessments. Screening and standardized assessments were previously part of usual care provided by these practitioners, with the exception of the medication and nutrition screens. Visits were conducted at patient's homes for housebound seniors, which is a less prominent aspect of usual care at SFHC. Patient and caregiver goals and preferences were identified at the initial visit, and referrals were arranged to involve other SCCP team members as
Journal of Research in Interprofessional Practice and Education

Vol. 3.1

March, 2013 
Care-Based Program for Seniors

Moore, Nair, Patterson, White, House, KadhimSaleh, \& Riva

Journal of Research in Interprofessional Practice and Education

Vol. 3.1

March, 2013
Journal of Research in Interprofessional Practice and Education

deemed necessary by the RPN, FP, or NP. For example, when medication complication risks were identified, the program pharmacist was consulted for a medication review. For diagnostic clarification and advice with more challenging management strategies, the visiting geriatrician became involved for either team consultation or direct patient care (25\% of cases).

\section{Team collaboration}

An important aspect of the pilot and ongoing program involves monthly teambased case meetings (approximately 1-2 new cases per month and 1-2 follow-up cases, 15-30 minutes per case). This meeting brings together all members of the SCCP team who were involved in care, including the visiting geriatrician and the family physician most responsible for the patient's care (referrer), to develop care plans for seniors with complex health problems. Face-to-face meetings allowed team problem solving, as well educational opportunities, through didactic sessions to learn about discipline-specific approaches to care and geriatric syndromes such as dementia, falls, polypharmacy, incontinence, and delirium (approximately 20-30 minutes per month). Team meetings provide the opportunity for referring practitioners to communicate/consult directly with the visiting geriatrician and the SCCP team and to participate in case-based and didactic learning relevant to their needs.

\section{Team communication}

SCCP team plans and follow-up arrangements were communicated, implemented, and negotiated with the patient's main care team, including community agency providers. Communication was facilitated through internal electronic messaging embedded within the patients' web-based electronic medical record (EMR), accessible to all practitioners within the circle of care.

\section{Methods}

Ethics approval for this study was obtained from the Hamilton Health Sciences, Faculty of Health Sciences, Research Ethics Board.

\section{Design}

This study used a "qualitative descriptive" approach to gain first-hand knowledge of the experience of nurses and physicians referring their patients to the SCCP in terms of what made this integrated program workable for them (benefits, advantages), what didn't work well (limitations, disadvantages), and what changes to their experience of caring for elderly patients were incurred (advantages, disadvantages). This approach is valuable for providing straight descriptions of events or experiences [41]. This approach provides useful data for small, independent research projects. The intent is to provide a description of our practitioners' experiences with the introduction of the SCCP, staying close to the data and using their own words. Aligned with qualitative description, inference is limited and founded in existing knowledge (clinical experience) of the research group [41]. 
Care-Based Program for Seniors

Moore, Nair, Patterson, White, House, KadhimSaleh, \& Riva

Journal of Research in Interprofessional Practice and Education

Vol. 3.1

March, 2013

\section{Journal of Research in Interprofessional Practice and Education}

Sample

We applied a purposive sampling strategy that made use of criterion sampling [42]. All nurses and physicians from within SFHC, who had referred at least 1 patient to the SCCP during the pilot phase, were invited to participate in order to gain a better understanding of how they experienced changes in caring for their elderly patients as a result of introducing the integrated SCCCP into their clinical environment. A criterion sample was obtained, in that all invited practitioners had referred at least one of their patients to the SCCP during the pilot phase study.

\section{Interviews}

A research assistant that was external to SFHC and arm's length from both investigators and participants was employed to obtain informed consent from participants and to conduct interviews. Given that the project investigators work with study participants in clinical, academic, and teaching activities within SFHC, it was important to minimize perceived pressure to participate and to reduce potential bias influenced by pre-established relationships. One-to-one, in-person interviews were conducted using a semi-structured interview guide. All interviews lasted between 20-25 minutes and were transcribed verbatim. The research assistant conducting interviews was apprised of the SCCP program (description, logistics, goals) prior to the interviews but did not participate in the design or implementation of the clinical program or study, which may have limited the depth of the interviews. The interview guide is attached as Appendix A.

\section{Analysis}

Data were analyzed using conventional content analysis [42]. Transcripts were coded independently by two members of the research team, who then compared codes to reach consensus on themes. Codes were derived directly from the text, staying close to the surface and intended meaning of words, in alignment with the qualitative descriptive framework. Codes were then collapsed into meaningful themes of benefits, limitations advantages, and disadvantages.

\section{Results}

\section{Participants}

Four nurse practitioners and five family physicians took part in an interview, which represented a $100 \%$ response rate. The average age of nurse practitioners was 49.8 years $(S D=8.3)$. Physicians on average were 45.2 years $(S D=9.0)$. All nurse practitioners were female and one family physician was male. The average number of years in practice for nurse practitioners and family physicians was 17.7 $(S D=9.3)$ and $14(S D=6.1)$ years, respectively. Most participants $(90 \%)$ were employed full time. All respondents had worked together at SFHC for approximately five years. All invited nurse practitioners $(N=4)$ and family physicians $(N=5)$ agreed to take part. 


\section{JRIPE}

110

Care-Based Program for Seniors

Moore, Nair, Patterson, White, House, KadhimSaleh, \& Riva
Journal of Research in Interprofessional Practice and Education

Vol. 3.1

March, 2013
Journal of Research in Interprofessional Practice and Education

Themes

Six interconnected themes emerged from the healthcare provider interviews:

- accessibility,

- the benefits of a multidisciplinary team,

- clear communication,

- learning,

- the preventive nature of the program, and

- the need for clarification of responsibilities.

Benefits and challenges to the SCCP were noted by participants and are described within each of the theme descriptions below. Quotes to highlight main findings are included in the text below, with each followed by clinician type and ID number.

\section{Theme 1: Accessibility}

Accessibility was a recurrent theme noted by clinicians and the most prominent theme overall. This theme included discussion about ease of process, location of specialty service, specialized care, and timeliness.

\section{Ease of process}

The process of involving patients in the SCCP was experienced as straightforward, and this contributed toward positive impressions of the program. One physician commented,

I felt there was a lot of helpful clinical information that came from involving the patient with geriatrics and at the same time not a lot of fuss or muss to getting that to happen. (Physician \#2)

One nurse commented on the process that accepted referrals from any healthcare provider (or learner) in the clinic. She noted that it allowed for a more responsive system that could address concerns identified from a variety of sources, an upgrade from the traditional physician-to-physician referral process. As she stated,

I think it works well ... if a problem is identified, a referral can be made by the resident, nurse, or staff doc on behalf of the patient or the patient's spouse; we can actually set-up the referral. (Nurse \#4)

\section{Location of service}

SCCP services provided either at patients' homes or at SFHC allowed patients to receive care in a comfortable and familiar setting: "They come here for their primary care so it's an extension of that. So their comfort level and how the system works, they already know" (Nurse \#1).

A physician expressed the same idea, commenting, "Having them here at the clinic ... provides easy accessibility ... they're comfortable coming here anyway for their family doctor. They come to the same place" (Physician \#5). This physi- 


\section{JRIPE}

111

Care-Based Program for Seniors

Moore, Nair, Patterson, White, House, KadhimSaleh, \& Riva
Journal of Research in Interprofessional Practice and Education

Vol. 3.1

March, 2013

\section{Journal of Research in Interprofessional Practice and Education}

cian further explained that having the SCCP situated on-site had benefits for practitioners as well due to the physical proximity:

I have talked to [team member] sort of on a non-formal consultation-type basis for some advice about a complicated patient of mine. She was able to offer me some advice. So it's nice to have them around ... for non-formal consultations as well as formal consultations. (Physician \#5)

\section{Specialized care}

Access to specialized expertise provided by the SCCP was a notable theme. Physicians acknowledged this when discussing the limits of their ability to provide optimal care. Their knowledge and scope of practice sometimes did not seem adequate to meet the needs of complex patients, and they appreciated the opportunity to connect and consult easily with members of the SCCP team who had other types of expertise. One physician explained,

The fact is most of the time when we're involving them ... it's because we're feeling at the end of our best understanding of how to manage that problem [seniors with complex care issues] ... it makes, can make a real difference between these patients continuing to do well in a community setting or potentially ending up in a situation where they're needing more support, like being in a nursing home. (Physician \#2)

Another physician expressed similar thoughts about three patients that he referred to the program. As he described, "All three of them were quite complicated cases, all involving issues around dementia, home safety, long-term care, optimization of medical management. So these were very, very complex patients" (Physician \#1). He elaborated:

I was feeling a bit stuck in terms of knowing how best to optimize their care and what more I could do for them. And with the involvement of the geriatrics team, I mean, all of a sudden the ideas about different things that could be implemented or trialed or offered or the services that were enhanced or set up for them, I think, made a significant difference. (Physician \#1)

A nurse observed that the addition of the SCCP allowed SFHC to continue to manage the needs of all but the most complex seniors. She stated:

with more and more seniors aging in the community and limited access to geriatricians ... it was a good match for the Family Health Team and the primary care system to be able to handle a lot of things in house ... and to refer out only the ones that need the specialized, more extensive care that we know is beyond our scope. (Nurse \#2) 


\section{JRIPE}

112

Care-Based Program for Seniors

Moore, Nair, Patterson, White, House, KadhimSaleh, \& Riva

Journal of Research in Interprofessional Practice and Education

Vol. 3.1

March, 2013
Journal of Research in Interprofessional Practice and Education

A physician perceived access to the specialized care provided by the SCCP was beneficial not only for the patient and patient's family, but also increased the physician's confidence in the patient's care:

And it really helped with a lot of the transitions they [patients] were experiencing and it certainly helped me to feel more confident and comfortable with how they were being managed. (Physician \#1)

\section{Timeliness}

Several practitioners identified accessibility of the SCCP as beneficial for their patients in terms of reduced wait times. A nurse stated:

I think it works well that now the clinic has somewhere that they can refer to without waiting months and months in the community. The length of the wait, like the waiting time to see a geriatrician, is decreased. (Nurse \#3)

One physician shared how helpful it was to be able to access input from the geriatric team in a timely fashion:

So, you know, I was having a problem and [the team] immediately got involved and came to a house call, which was really helpful early in the process. So I didn't have to wait on the consultation and it didn't take weeks to get that happening. It happened over the course of a few days. So they were able to come and give some input right away, which was very, very helpful. (Physician \#2)

Timeliness was also important in order to address issues as they arise for this population. As one physician stated:

You can deal with issues at the time the issues are presenting, and for one of my patients, who was in crisis around long-term placement and not managing at home, there were people there to help with the assessment when they really needed it. (Physician \#1)

\section{Theme 2: Multidisciplinary benefits}

The importance of multidisciplinary and collaborative aspects of the SCCP team emerged as a key theme. Both nurses and doctors appreciated involving different disciplines that provided information and support from several perspectives, which maximized care.

Multidisciplinary collaboration provided a diversity of suitable plans that were realistic to the primary care setting, and an improvement over management advice from outside specialists, as one physician stated:

You can get appropriate management ideas and plans from a variety of sources that are geared to the nature of the problems that our family medicine patients have ... you can have ideas from others, but if it's not practical and if it's not helpful, that doesn't matter at all. But 


\section{JRIPE}

113

Care-Based Program for Seniors

Moore, Nair, Patterson, White, House, KadhimSaleh, \& Riva

Journal of Research in Interprofessional Practice and Education

Vol. 3.1

March, 2013

\section{Journal of Research in Interprofessional Practice and Education}

this is, I mean, this is really understanding, understanding family medicine perspective and family medicine patients. (Physician \#3)

Multidisciplinary perspectives focusing on a diversity of care issues created a synergy greater than the individual practitioner contributions:

It was great to have a geriatrician there that I could have access to, to ask my questions. And it was wonderful to get input from all the different disciplines because they were all looking at different aspects of the patient's care ... that provides the full picture for you. (Physician \#4)

The case-based team meeting was identified as the platform for facilitating multidisciplinary collaborative processes. As stated by one nurse,

the case presentation, I think, worked well ... because it brought in different perspectives ... all people's expertise are at the table and also the learners are involved ... that maximized care and decision making. (Nurse \#1)

Due to the large size of the care team, challenges with bringing all team members together limited full participation with case-based meetings. As one nurse stated: "organizing the time for all the appropriate providers to be involved was challenging" (Nurse \#1).

\section{Theme 3: Clear communication}

Communication was a theme described primarily by family physicians, who expressed the importance of clear, concise communication with the SCCP. Clear and timely communication kept all healthcare providers up-to-date on patient care and made it possible for recommended changes or actions to be implemented efficiently. One physician stated: "I found that the communication back was very timely and useful," adding, "I got feedback from all the members of the team on a few levels" (Physician \#2).

Another physician explained:

I think it [communication] leads to better patient care outcomes because it's so timely and accessible and appropriate. So, the communication is so excellent, so there's no delays. You can implement changes right away. And I think that it's more efficient and I think there's less costly interventions done because of the better and more timely communication. (Physician \#3)

One nurse commented on the advantages of communication strategies used by the SCCP team in comparison to traditional consultant communications: "if we refer to a geriatrician or a geriatrics program outside, we're relying on consult notes, so communication is more difficult" (Nurse \#1). 
Care-Based Program for Seniors

Moore, Nair, Patterson, White, House, KadhimSaleh, \& Riva

Journal of Research in Interprofessional Practice and Education

Vol. 3.1

March, 2013

\section{Journal of Research in Interprofessional Practice and Education}

\section{Theme 4: Preventive nature of the program}

Many of the practitioners interviewed discussed the importance of the preventive nature of the program and its ability to identify and intervene in problems early. This allowed plans to be put in place to keep issues from becoming crises, as explained by one nurse commenting on the invisibility of elderly in the practice and the system's inability to identify problems before a crisis: "we don't see them, we have a large population here and a large population of elderly ... until they get into a crisis ... somebody falls, breaks a hip, or is unable to cope." She continued: "So by recognizing it before they get to that crisis, we could perhaps put something in place for them so they would have supports and they wouldn't get into that crisis situation" (Nurse \#4).

This sentiment was echoed by most of the nurses interviewed. The ability to intervene early was seen as beneficial for patient caregivers as well: "Intercepting safety concerns and not just identifying them but putting an action plan together that gives caregiver relief" (Nurse \#2).

Identifying problems before a critical point in the continuum of care was perceived as potentially contributing to maintaining seniors in their environment of choice by delaying placement to long-term care. One physician reflected:

these are complex and potentially vulnerable patients who are on the edge, I think, of being able to continue to manage in the community. And I think this service, a service like this is essential to build capacity and confidence among family docs to keep managing those patients in their current setting. (Physician \#2)

\section{Theme 5: Learning}

Practitioners reported educational benefits provided by the program for themselves, patients, and learners. Clinicians valued the education and support that was available when needed and felt that it contributed toward increased knowledge and skills in managing clinically challenging elderly patients: "this is essential to build capacity and confidence among family docs to keep managing those patients in their current setting" (Physician \#2).

Another nurse commented on the importance of involving the main care providers (physicians and nurses) as a learning advantage over traditional outside referrals, explaining,

What's working well is that the learners and the main providers are in the loop. It's not taken away and geriatrics totally manages them ... having the program here [allows] knowledge transfer to the main providers outside of the [SCCP] program and for the learners, too. (Nurse \#1)

Several nurses discussed involvement of learners in the program and how they benefited from exposure to the team's expertise. One explained how the program is great training for different types of learners for their future practices. She stated: 
Care-Based Program for Seniors

Moore, Nair, Patterson, White, House, KadhimSaleh, \& Riva

Journal of Research in Interprofessional Practice and Education

Vol. 3.1

March, 2013

\section{Journal of Research in Interprofessional Practice and Education}

I do think it's a great opportunity for resident and nurse practitioner student learning, pharmacy student learning as well ... [which will allow learners to function] at a much higher level when they are in their own practices. (Nurse \#2)

Expanded awareness about specific patients with complex health problems across multiple healthcare providers within the clinic was reassuring to one physician, who stated, "I get input from different disciplines in the clinic and they become familiar with my patient and you're all now on the same page with the approach to this patient and our plan of management" (Physician \#4).

\section{Theme 6: Need for clarification of responsibilities}

A key barrier was confusion around roles that resulted from patient involvement in the SCCP. One physician felt that patients stopped communicating with their own family physicians once they were enrolled in the SCCP, perhaps because they were not clear about who was providing care. He explained, "all these different care providers [become] involved. It might be confusing for families and patients to know who they should follow up with and when they should follow up," suggesting that the team "could emphasize regular follow-up with their regular family physician" (Physician \#1).

Another physician explained that the confusion about roles also extends to practitioners:

So for instance, when a patient phone calls come [sic] in, let's say from a family member, I don't know if that's my job to handle it or if it's their [SCCP] job to handle it, or just not knowing how things are sort of working. (Physician \#2)

Due to conflicting schedules, one family physician found it difficult to arrange in-person contact with the team and to understand which team member was most accountable for her patient, stating, "with all our roving times that we're all available sometimes, it's hard to connect with the, the person most responsible" (Physician \#5).

\section{Summary of results}

Nurses and physicians referring their elderly patients to the SCCP identified ease of access, reduced wait times, enhanced bidirectional communication, as well as realistic recommendations from practitioners based within primary care as improvements to care processes that made this multidisciplinary, integrated program workable for them. Multidisciplinary perspectives contributed to program effectiveness through expanded options for patients and improved the quality of care for seniors, possibly through creative synergies that were greater than individual practitioner contributions. Perceived preventive aspects of the program also contributed to improved quality of care for seniors, which was considered critical for the frail elderly to minimize a spiral of complications and key to maintaining them in their 
116

Care-Based Program for Seniors

Moore, Nair, Patterson, White, House, KadhimSaleh, \& Riva

Journal of Research in Interprofessional Practice and Education

Vol. 3.1

March, 2013 environment of choice. Introducing the SCCP to the clinical environment where referring professionals work was associated with advantages of enhanced learning that increased comfort and skills with caring for elderly patients. Increased comfort was connected to feeling supported when referrers were at the limits of their capacity to provide optimal care, as well as increasing awareness within the clinic of seniors with complex health problems to ensure consistency of management approaches. There was a spill-over effect with introducing the SCCP that increased skills of referring providers. Knowledge transfer occurred mainly by keeping care within the clinic and by keeping main care providers (and learners) in the loop. This was achieved through participation in case-based team meetings, didactic learning opportunities, and inclusive communication strategies. Problems with role clarification and task assignment created confusion for patients and referrers and were perceived as disadvantages for referrers.

\section{Discussion}

This study has provided an important and unique focus on those who refer patients to specialized programs within their care environment. Success and continued uptake of such programs depend on having sustained referrals. Understanding the perspectives of referrers allows for meaningful reflection on what is working and what is not and creates a mechanism for modifying and improving program delivery based on feedback from those who are in a position to recommend program use. Overall, the perspectives of those who referred patients to the SCCP were positive. The main benefits and advantages for front-line practitioners referring their elderly patients to the SCCP were improved care processes, improved quality of care, as well as increased comfort and confidence when managing their elderly patients. The one main barrier cited related to some referrers not having an understanding of how they would or should continue involvement within the patient's circle of care.

The success of this program can partly be attributed to the grassroots nature of the evaluation of the SCCP, as this was a program that was inspired by needs of family medicine patients and practitioners; identified by family medicine practitioners; and developed, implemented, and delivered by the same family medicine practitioners in collaboration with specialized geriatric and community agency partners. This is similar to other programs that have also attributed key factors in the initiation and continuation of programs to starting small, based on an identified need, completing pilot work, and engaging leadership for support [43]. These findings have important implications for clinical practice and health services policy for up-scaling grassroots initiatives.

Face-to-face formal (team meetings) and informal (hallway) communication as well as electronic Internet-based record sharing highlighted that multiple forms of communication help to solidify the benefits noted by participants. This finding is reminiscent of other literature that found advantages of full integration occurred when charting in shared clinical records. This enhanced efficiency and improved communication between primary care and specialist services, creating opportuni- 
Care-Based Program for Seniors

Moore, Nair, Patterson, White, House, KadhimSaleh, \& Riva

Journal of Research in Interprofessional Practice and Education

Vol. 3.1

March, 2013

\section{Journal of Research in Interprofessional Practice and Education}

ties to discuss patients who might not need to be seen or who had been seen at a previous visit [35].

The integration of a specialist into the primary care setting has also been explored in other studies, with many focusing on mental health. Lessons learned from these studies were similar to this study, with clinicians reporting increase in skill related to specialist expertise as well as greater efficiency in how care is delivered $[35,43,44]$. For example, specialist collaboration within primary care provided resources and back up that permitted the primary care clinician to more comfortably fulfill depression-screening, more aggressively formulate depressive diagnoses, and more effectively manage depressive episodes [44]. The most recent generation of research on mental health collaboration within primary care has focused on the elderly and concluded that consultative roles allow the specialist to indirectly but efficiently serve a large number of patients [44]. Rates of referrals to outpatient specialty psychiatry clinics by family physicians, participating in mental health integrated programs, decreased by $66 \%$ [35]. For geriatricians, such findings are of note given the insufficient number of geriatric specialists to meet all clinical needs.

\section{Study limitations}

This thematic analysis focused on referrers to the SCCP. There are other stakeholders important for uptake and sustainability of integrated programming, such as healthcare professionals delivering integrated care, patients receiving care, and learners participating in care. Future research should evaluate these perspectives.

Further, due to the small sample size, participants may have been less likely to report negative comments because of concern about being identified, especially as SCCP practitioners work closely with study respondents in multiple clinical and academic activities at SFHC. Having an interviewer not affiliated with SFHC was a tactic that was used to minimize participant concerns about sharing perceptions about their colleagues.

\section{Conclusions}

Development and evaluation of new models of care for an aging population that are aligned with current reform directions are necessary to address what has been described as one of the most challenging healthcare problems of our times. This study found that the introduction of a multidisciplinary, integrated program for seniors improved care processes, improved quality of care, and enhanced the experience of referring practitioners caring for elderly patients. Unclear communication of roles and responsibilities created confusion and has subsequently been addressed through clear role assignment within the team. Assessing clinical impact and examining perspectives of patients, caregivers, and other health professionals involved in the SCCP, as well as cost/benefit evaluations are planned to further understand the value of these approaches, which have broad implications for the design and delivery of primary care. 
JRIPE

118

Care-Based Program for Seniors

Moore, Nair, Patterson, White, House, KadhimSaleh, \& Riva

Journal of Research in Interprofessional Practice and Education

Vol. 3.1

March, 2013

\section{Journal of Research in Interprofessional Practice and Education}

\section{Acknowledgements}

We thank the physicians and nurses who shared their perspectives with us. We would also like to thank the Department of Family Medicine, McMaster University, and the Ontario Ministry of Health and Long-Term Care for their funding support. Views expressed do not necessarily reflect those of the Province of Ontario, Canada.

\section{Abbreviations}

EMR - Electronic Medical Record

FP - Family Physician

NP - Nurse Practitioner

RPN - Registered Practical Nurse

SCCP - Seniors Collaborative Care Program

SFHC - Stonechurch Family Health Centre

\section{References}

1. Statistics Canada. (2010). Population Projections for Canada, Provinces and Territories 2009 to 2036. Ottawa, ON, Canada: Catalogue no. 91-520-X.

2. Adams, W.L., McIlvain, H.E., Lacy, N.L, Magsi, H., Crabtree, B.F., Yenny, S.K., \& Sitorius MA. (2002). Primary care for elderly people: Why do doctors find it so hard? Gerontologist, 42, 835-842.

3. Torrible, S., Diachun, L., Rolfson, D., Dunbrell, A., \& Hogan, D. (2006). Improving recruitment into geriatric medicine in Canada: Findings and recommendations from the geriatric recruitment issues study. Journal of American Geriatric Society, 54(9), 1453-1462.

4. Mickan, S., Hoffman, \& S.J., Nasmith, L. (2010). Collaborative practice in a global health context: Common themes from developed and developing countries. Journal of Interprofessional Care, 24(5), 492-502.

5. Price, D., Hilts, L., McCarthy, L., Walsh, A., \& Dykeman, L. (2009). Interprofessional education in family medicine teaching units. Canadian Family Physician, 55, 901-901.

6. Oandasan, I., \& Closson, T. (2007), Inter_professional_Care: Blueprint for_Action. Toronto,_ON:

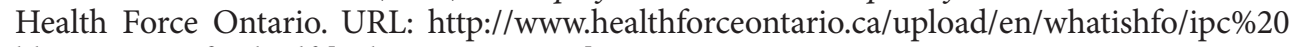

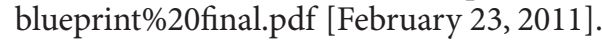

7. Lee, L., Hillier, L.M., Stolee, P., Heckman, G., Gagnon, M., McAiney, C.A., \& Harvey, D. (2010). Enhancing dementia care: A primary care-based memory clinic. Journal of the American Geriatric Society, 58, 2197-2204.

8. Moore, A., Patterson, C., White J., House, S., Riva, J.J., Nair, K., Brown, A., Kadhim-Saleh, A., \& McCann, D. (2012). Interprofessional and integrated care of the elderly in a family health team. Canadian Family Physician, 58(8), e436-e441.

9. Boult, C., Reider, L., Frey, K., Leff, B., Boyd, C.M., Wolff, J.L., Wegener, S., Marsteller, J., Karm, L., \& Scharfstein, D. (2008). Early effects of "guided care" on the quality of health care for multimorbid older persons: A cluster-randomized controlled trial. The Jounrals of Gerontology, Series A: Biological Sciences and Medical Sciences, 63, 321-327.

10. Boyd, C.M., Shadmi, E., Conwell, L.J., Griswold, M., Leff, B., Brager, R., Sylvia, M., \& Boult, C. (2008). A pilot test of the effect of guided care on the quality of primary care experiences for multimorbid older adults. Journal of General Internal Medicine, 23, 536-42.

11. Baxter, P., \& Markle-Reid, M. (2009). An interprofessional team approach to fall prevention for older home care clients 'at risk' of falling: Health care providers share their experiences. International Jounral of Integrated Care, 9, e15.

12. Hughes, S.L., Weaver, F.M., Giobbie-Hurder, A., Manheim, L., Henderson, W., Kubal, J.D., Ulasevich, A., \& Cummings, J. (2000). Effectiveness of team-managed home-based primary care: A randomized multicenter trial. The Journal of the American Medical Association, 284, 2877-2885.

13. Arbaje, A.I., Maron, D.D., Yu, Q., Wendel, V.I., Tanner, E., Boult, C., Eubank, K.J., \& Durso, S.C. (2010). The geriatric floating interdisciplinary transition team. Journal of the American Geriatrics Society, 58, 364-370. 
119

Care-Based Program for Seniors

Moore, Nair, Patterson, White, House, KadhimSaleh, \& Riva
Journal of Research in Interprofessional Practice and Education

Vol. 3.1

March, 2013
14. Callahan, C.M., Boustani, M.A., Unverzagt, F.W., Austrom, M.G., Damush, T.M., Perkins, A.J., Fultz, B.A., Hui, S.L., Counsell, S.R., \& Hendrie, H.C. (2006). Effectiveness of collaborative care for older adults with alzheimer disease in primary care: A randomized controlled trial. The Journal of the American Medical Association, 295(18), 2148-2157.

15. Chew-Graham, C.A., Lovell, K., Roberts, C., Baldwin, R., Morley, M., Burns, A., Richards, D., \& Burroughs, H. (2007). A randomised controlled trial to test the feasibility of a collaborative care model for the management of depression in older people. The British Journal of General Practice, 57, 364-370.

16. Slimmer, L. (2003). A collaborative care management programme in a primary care setting was effective for older adults with late life depression. Evidence Based Nursing, 6, 91.

17. Bernabei, R., Landi, F., Gambassi, G., Sgadari, A., Zuccala, G., Mor V., Rubenstein, L.Z., \& Carbonin, P. (1998). Randomised trial of impact of model of integrated care and case management for older people living in the community. British Medical Journal, 316, 1348-1351.

18. Rabow, M.W., Dibble, S.L., Pantilat, S.Z., McPhee, S.J. (2004), The comprehensive care team: A controlled trial of outpatient palliative medicine consultation. Archives of Internal Medicine, 164: 83-91.

19. Eng, C. Pedulla, J., Eleazer, G.P., McCann, R., Fox, N. (1997), Program of all inclusive care of the elderly: An innovative model of integrative geriatric care and financing. Journal of the American Geristrics Society, 45, 223-232.

20. Boult, C., Green, A.F., Boult, L.B., Pacala, J.T., Snyder, C., \& Leff, B. (2009). Successful models of comprehensive care for older adults with chronic conditions: Evidence for the institute of medicine's "retooling for an aging america" report. Journal of the American Geriatrics Society, 57, $2328-2337$.

21. Bartels, S.J., Coakley, E.H., Zubritsky, C., Ware, J.H., Miles, K.Mm, Areán, P.A., Chen, H., Oslin, D.W., Llorente, M.D., Costantino, G., Quijano, L., McIntyre, J.S., Linkins, K.W., Oxman, T.E., Maxwell, J., \& Levkoff, S.E. (2004). Improving access to geriatric mental health services: A randomized trial comparing treatment engagement with integrated versus enhanced referral care for depression, anxiety, and at-risk alcohol use. The American Journal of Psychiatry, 161, 1455-1462.

22. Arean, P.A., Ayalon, L., Hunkeler, E., Lin, E.H., Tang, L., Harpole, L., Hendrie, H., Williams, J.W. Jr, Unützer, J. (2005). Improving depression care for older, minority patients in primary care. Medical Care, 43, 381-390.

23. Bruce, M.L., Ten Have, T.R., Reynolds, C.F. 3rd, Katz II., Schulberg, H.C., Mulsant, B.H., Brown G.K., McAvay, G.J., Pearson, J.L., \& Alexopoulos G.S. (2004). Reducing suicidal ideation and depressive symptoms in depressed older primary care patients: A randomized controlled trial. Journal of the American Medical Association, 291, 1081-1091.

24. Callahan, C.M., Kroenke, K., Counsell, S.R., Hendrie, H.C., Perkins, A.J., Katon, W., Noel, P.H., Harpole, L., Hunkeler, E.M., \& Unützer J. (2005). Treatment of depression improves physical functioning in older adults. Jounral of the American Geriatrics Society, 53, 367-373.

25. Hunkeler, E.M., Katon, W., Tang, L., Williams, J.W. Jr,, Kroenke, K., Lin, E.H., Harpole, L.H, Areán P, Levine S, Grypma LM, Hargreaves WA, \& Unützer J (2006). Long term outcomes from the IMPACT randomised trial for depressed elderly patients in primary care. British Medical Jounral, 332, 259-263.

26. Rosemann, T., Joos, S., Laux, G., Gensichen, J., Szecsenyi, J. (2007). Case management of arthritis patients in primary care: A cluster-randomized controlled trial. Arthritis and Rheumatism, 57, 1390-1397.

27. Gray, D., Armstrong, C.D., Dahrouge, S., Hogg, W., \& Zhang, W. (2010). Cost-effectiveness of anticipatory and preventive multidisciplinary team care for complex patients: Evidence from a randomized controlled trial. Canadian Family Physician, 56, 20-29.

28. Counsell, S., Callahan, C.M., Buttar, A., Clark, D.O., Frank, K.I. (2006). Geriatric Resources for Assessment and Care of Elders (GRACE): A new model of primary care for low-income seniors. Journal of the American Geriatrics Society, 54, 1136-1141.

29. Katon, W.J., Schoenbaum, M., Fan, M.Y., Callahan, C.M., Williams, J. Jr., Hunkeler, E., Harpole, L., Zhou X.H., Langston C., \& Unützer J. (2005). Cost-effectiveness of improving primary care treatment of late-life depression. Archives of General Psychiatry, 62, 1313-1320.

30. Beck, A., Scott, J., Williams, P. Robertson, B., Jackson, D., Gade, G., Cowan, P. (1997). A randomized trial of group outpatient visits for chronically ill older HMO members: The cooperative health care clinic Journal of the American Geriatrics Society, 45, 543-549. 


\section{JRIPE}

120

Care-Based Program for Seniors

Moore, Nair, Patterson, White, House, KadhimSaleh, \& Riva

\section{Journal of Research in Interprofessional Practice and Education}

31. Windham, G., Bennett, R., Gottlieb, S. (2003), Care management interventions for older patients with congestive heart failure. American Journal of Managed Care, 9, 447-461.

32. Gallo, J. J., Zubritsky, C., Maxwell, J., Nazar, M., Bogner, H.R., Quijano, L.M., Syropoulos, H.J., Cheal, K.L., Chen, H., Sanchez, H., Dodson, J., Levkoff, S.E. (2004). Primary care clinicians evaluate integrated and referral models of behavioral health care for older adults: Results from a multisite effectiveness trial (PRISM-E). Annals of Family Medicine, 2(4), 305-309.

33. Wright, B., Lockyer, J., Fidler, H., \& Hofmeister, M. (2007). Roles and responsibilities of family physicians on geriatric health care teams. Health care team members' perspectives. Canadian Family Physician, 53(11), 1954-955.

34. Paquette-Warren, J., Vingilis, E., Greenslade, J., \& Newnam, S. (2006). What do practitioners think? A qualitative study of a shared care mental health and nutrition primary care program. International Journal of Intergrated Care, 6, e18-e20.

35. Kates, N., Crustolo, A., Farrar, S., Nikolauo, L., Akerman, S., Brown, S. (2002). Mental Health Care and Nutrition: Integrating Specialist Services Into Primary Care. Canadian Family Physician, 48, 1898-1903.

36. Yesavage, J.A., Brink, T.L., Rose, T., Lum, O., Huang, V., Adey, M., Leirer, V.O. (1982-1983). Development and validation of a geriatric depression screening scale: a preliminary report. Journal of Psychiatric Research, 17(1), 37-49.

37. Levy, H.B. (2003). Self-administered Medication Risk Questionnaire in an elderly population. Ann of Pharmacotherapy, 37(7), 982-987.

38. Keller, H.H., Goy, R., Kane, S.L. (2005). Validity and reliability of SCREEN II (Seniors in the community: Risk evaluation for eating and nutrition, Version II). European Journal of Clinical Nutrition, 59, 1149-1157.

39. Rubenstein, L.Z., Powers, C.M., \& Maclean, C.H. (2001). Quality indicators for the management and prevention of falls and mobility problems in vulnerable elders. Annals of Internal Medicine, 135(8), 686-693.

40. Patterson, C., Feightner, J.W., Garcia, A., Hsiung, R., Macknight, C., \& Sadovnik, D. (2008). Diagnosis and treatment of dementia 1: Risk assessment and primary prevention of Alzheimer disease. Canadian Medical Association Journal, 178(5), 548-556.

41. Neergaard, M.A., Olesen, F., Andersen, R.S.R, \& Sondergaard, J. (2009). Qualitative description the poor cousin of health research? BioMed Central: Medical Research Methodology, 9(52): 1471-2288.

42. Miles, M.B., Huberman, A.M. (1994). Qualitative Data Analysis [2nd edition]. Thousand Oaks, CA: Sage Publications.

43. Steiner, B., Denham, A., Ashkin, E., Newton, W., Woth, T., \& Dobson, A. (2008). Community Care of North Carolina: Improving Care Through Community Health Networks. Annals of Family Medicine, 6, 361-367.

44. Oxman, T., Dietrick, A., \& Schulberg, H. (2003). The Depression Care Manager and Mental Health Specialist as Collaborators Within Primary Care. Journal of Geriatric Psychiatry, 11, 507-516.
Journal of Research in Interprofessional Practice and Education

Vol. 3.1

March, 2013 
121

Care-Based Program

for Seniors

Moore, Nair, Patterson, White, House, KadhimSaleh, \& Riva

\section{Appendix A Interview guide}

- What is your role in the clinic?

- How many years have you been in practice?

- In your opinion what worked well with the program. (Probe: What were the benefits? who benefitted?)

- What parts of the program did not work well? (Probe: What problems / limitations did you encounter? What would you change about the program?)

- Are there advantages of this program? If so, can you describe them?

- Are there disadvantages of this program? If so, can you describe them?

- Any other comments or feedback? 